\title{
Bacterial Cellulose-Alginate Membrane for Dehydration of Biodiesel-Methanol Mixtures
}

\author{
Theerawat Suratago ${ }^{1, a}$, Panu Panitchakarn ${ }^{1}$, Pattanan Kerdlarpphon ${ }^{1}$, \\ Napat Rungpeerapong ${ }^{1}$, Vorakan Burapatan ${ }^{2}$, and Muenduen Phisalaphong ${ }^{1, \mathrm{~b}, *}$ \\ 1 Chemical Engineering Research Unit for Value Adding of Bioresources, Department of Chemical \\ Engineering, Faculty of Engineering, Chulalongkorn University, Bangkok 10330, Thailand \\ 2 PTT Research and Technology Institute, Phahonyothin Road KM 78, Wang Noi, Phra Nakhon Si \\ Ayutthaya 13170, Thailand \\ E-mail: atheerawat_j227@hotmail.com, bmuenduen.p@chula.ac.th (Corresponding author)
}

\begin{abstract}
Pervaporation, a membrane-based technique, is taken into consideration in order to separate water from biodiesel-methanol mixtures. Several operational conditions in biodiesel production could cause water contamination into the reaction mixture, which can affect biodiesel production and quality. In this study, bacterial cellulose-alginate (BCA) nanocomposite film was applied as a selective membrane in order to separate water from biodiesel-methanol mixtures using pervaporation. For effective operation, factors that affected the performance in the pervaporation, such as concentration of water in the biodiesel-methanol mixtures and temperature of the process were investigated. It was demonstrated that, the $\mathrm{BCA}$ membrane has good potential for removing water from the biodiesel-methanol mixtures. Under a permeate pressure of $10 \mathrm{mmHg}$ and $30^{\circ} \mathrm{C}$, the $\mathrm{BCA}$ membrane could separate water from the mixture containing methyl ester (C10:0): methanol: water at a weight ratio of 42.3: 52.7: 5 with a total permeate flux of $148 \mathrm{~g} /\left(\mathrm{m}^{2} \mathrm{~h}\right)$ and a water selectivity of 332 . The permeate was contained $94.5 \% \mathrm{w} / \mathrm{w}$ water and methyl ester was completely rejected by the BCA membrane. The increase of water concentration in biodiesel-methanol mixtures and the temperature rise resulted in an increase in the permeate flux but lowered the selectivity.
\end{abstract}

Keywords: Biodiesel, pervaporation, bacterial cellulose, alginate, nanocomposite membrane.

ENGINEERING JOURNAL Volume 20 Issue 5

Received 19 November 2015

Accepted 8 March 2016

Published 25 November 2016

Online at http://www.engj.org/

DOI:10.4186/ej.2016.20.5.145 


\section{Introduction}

Biodiesel is environmentally friendly and renewable alternative energy. Nowadays, biodiesel is produced by well-known process called transesterification and esterification. Regarding the reactions, vegetable oils [1], free fatty acid $[2,3]$ or waste cooking oil (WCO) $[4,5]$ are reacted with short-chain alcohols (typically methanol, ethanol, propanol and butanol) [6] using catalysts (e.g. $\mathrm{NaOH}, \mathrm{KOH}, \mathrm{H}_{2} \mathrm{SO}_{4}$ ) and lipase enzymes. Water is a major source of biodiesel contamination. Substrates for biodiesel productions such as alcohols and waste oils can be contaminated with water. Water is also a byproduct of the esterification reaction. The presence of water in the system can lead to many problems. It can cause corrosion of engine fuel system components, which becomes acidic with time and then attacks fuel storage tanks. Water can cause catalyst deactivation and lowers the biodiesel conversion yield and quality. The biodiesel production and quality could be improved by removal of the water produced during the esterification process using pervaporation $[7,8]$.

Pervaporation technique has been developed for selective separation of liquid substances such as organic solvents and water-organic mixtures [9] and it has been considered as an effective separation processes due to its high selectivity, low energy consumption, and low waste generation [10]. In the pervaporation process, a liquid feed is brought in contact with one side of a dense membrane and a vacuum is drawn on the other side of the membrane, producing a permeate vapor, which later is condensed by the cold trap into liquid. The driving force for permeation is a vapor pressure difference across the membrane. Selectivity is obtained by selective dissolution of substances into the membrane and the difference in diffusion of each substance through the membrane [9]. The physico-chemical properties of the membranes play an important role in pervaporation performance. A wide range of organic polymers such as polyvinyl alcohol (PVA) [11, 12], polyamide [13, 14], alginate [15, 16], chitosan [15, 17-19], Konjac glucomannan [19] have been applied as hydrophilic membranes for dehydration by pervaporation. Recently, bacterial cellulose-alginate (BCA) nanocomposite has been successfully developed as an effective membrane to separate water from ethanol-water mixtures [20]. In this study BCA membrane was further investigated as a selective membrane for removal of water from biodiesel-methanol mixtures. The effects of water content in feed synthetic biodiesel-methanol mixtures $(5 \%$ and $10 \% \mathrm{w} / \mathrm{w})$ and operating temperatures $\left(30-60{ }^{\circ} \mathrm{C}\right)$ on the pervaporation performance in the term of permeate flux and selectivity were investigated.

\section{Materials and Methods}

\subsection{Materials}

Methyl ester with the average molecular weight of 186 (PTTT Global Chemical Public Co., Ltd., Bangkok, Thailand) was used as biodiesel in this study. The composition of the biodiesel is C8 $(<0.01 \% \mathrm{w} / \mathrm{w}), \mathrm{C} 10$ $(98.92 \% \mathrm{w} / \mathrm{w})$, and $\mathrm{C} 12(0.73 \% \mathrm{w} / \mathrm{w})$. Sodium hydroxide, methanol $\left(\mathrm{CH}_{4} \mathrm{O}\right)$, sucrose, ammonium sulfate and calcium chloride dehydrate were purchased from Ajax Finechem Pty Ltd. (Australia). Acetic acid was purchased from Mallinckrodt Chemicals (USA) and sodium alginate was purchased from Acros Organics (USA). The stock culture of Acetobacter xylinum AGR 60 was kindly supplied by Pramote Tammarat, the Institute of Food Research and Product Development, Kasetsart University, Bangkok, Thailand.

\subsection{Membrane Preparation}

The BC membrane was prepared by biosynthesis using coconut water as a based substance. The coconut water medium was mixed with $0.5 \%(\mathrm{w} / \mathrm{v})$ ammonium sulfate, $5.0 \%(\mathrm{w} / \mathrm{v})$ sucrose, and $1.0 \%$ acetic acid solution $(30 \%, \mathrm{v} / \mathrm{v})$ and sterilized at $110{ }^{\circ} \mathrm{C}$ for $5 \mathrm{~min}$. The concentration of $A$. xylinum stock culture was measured as optical density (OD) at $620 \mathrm{~nm}$ (UV-2450 spectrophotometer, Shimadzu Corp., Japan), which was $~ 0.4$. The steriled medium $(75 \mathrm{~mL})$ was added by $A$. xylinum stock culture $(4 \mathrm{~mL})$ in a sterile petri dish (diameter $14 \mathrm{~cm}$ ) and statically incubated at $30 \pm 2{ }^{\circ} \mathrm{C}$ for 7 days. The bacterial pellicles were treated with $1 \%$ (w/v) sodium hydroxide solution for $24 \mathrm{~h}$, washed with running water for $30 \mathrm{~min}$ and then rinsed with deionized (DI) water until the $\mathrm{pH}$ reached 7 . The cleaned pellicles were immersed in sodium alginate solution $(3 \% \mathrm{w} / \mathrm{v})$ at $50 \pm 2{ }^{\circ} \mathrm{C}$ for 5 days. The BCA pellicles were rinsed with DI water, cross-linked with $5 \%(\mathrm{w} / \mathrm{v}) \mathrm{CaCl}_{2}$ for $3 \mathrm{~h}$, rinsed again with DI water, and dried in ambient air for 3 days. 


\subsection{Characterization}

The BC and BCA thicknesses were measured using a thickness gauge (Mitutoyo 7301, Japan). The crosssectional and surface morphologies of $\mathrm{BC}$ and $\mathrm{BCA}$ were examined using scanning electron microscopy (SEM; JSM-7610F, JEOL, USA) at $15 \mathrm{kV}$ and magnifications of 20,000 and 10,000. Membrane samples were prepared by immersion in liquid nitrogen, immediately followed by cutting and coating with a thin layer of gold. The surface areas and average pore sizes of the membranes were determined using a Brunauer-Emmett-Teller (BET) surface area analyzer (Autosorb-1, USA). Physical adsorption of nitrogen gas was measured at $77.35 \mathrm{~K}$. The contact angles were measured using a CAM-PLUS (USA) contact angle meter equipped with a charge-coupled device camera. A droplet $(5 \mu \mathrm{L})$ of DI water was randomly dropped onto the dry membrane. The contact angles against five different spots were averaged.

\subsection{Pervaporation Experiments}

Biodiesel-methanol mixtures at a mole ratio of methyl ester: methanol of 1: 5 containing water at $5 \%$ and $10 \%(\mathrm{w} / \mathrm{w})$ were used as the initial feed in a $900 \mathrm{~mL}$ vessel equipped with a heating bar, temperature sensor, and four flat-blade disk-turbine impellers. The pervaporation schematic is shown in Fig. 1. The liquid mixture in the vessel was circulated at $150 \mathrm{rpm}$ and the operating temperature was controlled at 30,40,50, and $60{ }^{\circ} \mathrm{C}$ throughout the experiments. In the separation compartment, a prepared $\mathrm{BC}$ or BCA membrane of effective area $19.625 \mathrm{~cm}^{2}$ was mounted at the bottom of the feed vessel. The permeate compartment was evacuated at $10 \mathrm{mmHg}$, using a high-vacuum pump (Model RV5, Edwards, West Sussex, UK). The permeate vapor across the membrane was collected after $2 \mathrm{~h}$ in a cold trap immersed in liquid nitrogen. The quantities of water in the permeate solution were determined using a Karl Fischer analyzer (C20 Compact KF Coulometer, Germany).

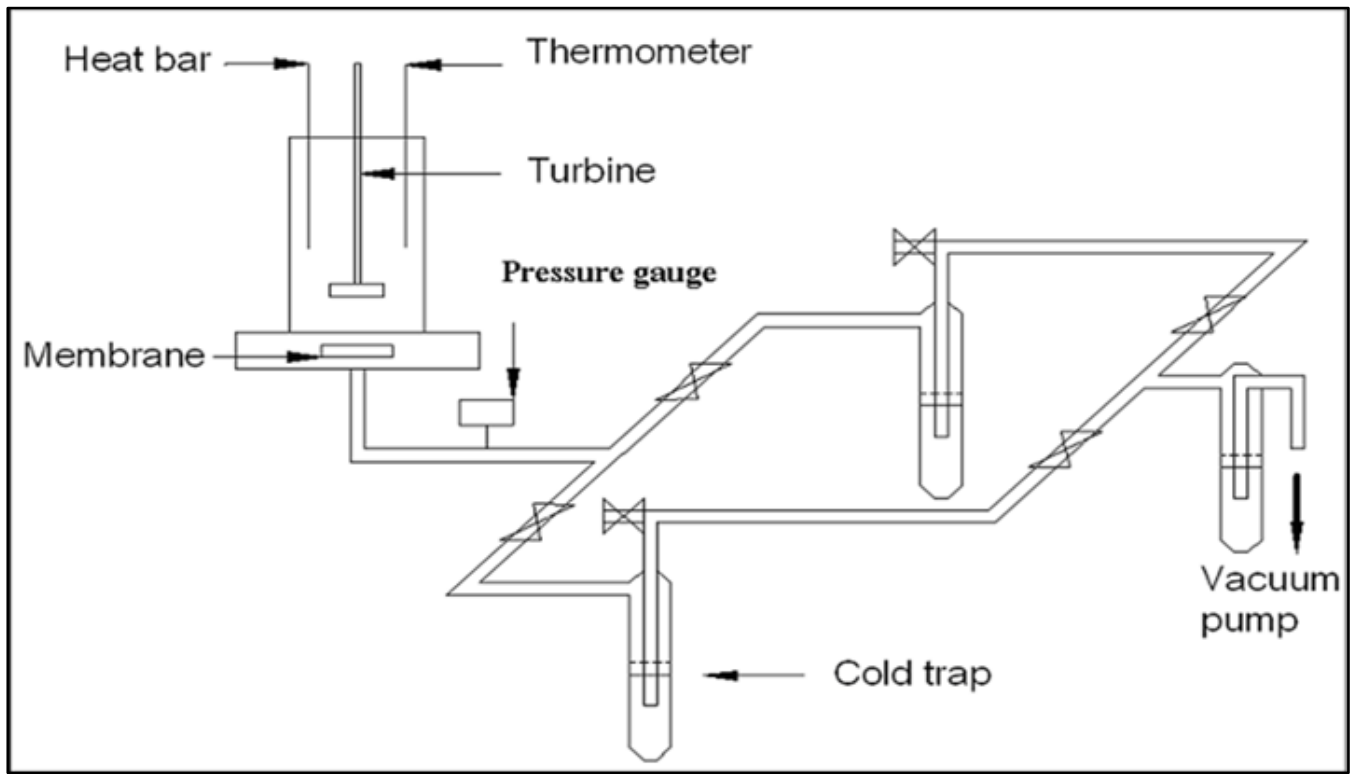

Fig. 1. Schematic diagram of pervaporation experiment set-up.

The quantities of biodiesel and methanol were analyzed by Gas Chromatography (Shimadzu 14B, Japan).The permeates flux (J) calculated as follows:

$$
J=\frac{Q}{A t}
$$

where $Q$ is the mass of permeate collected in time $t, A$ is the effective membrane area.

The selectivity $(\alpha)$ was calculated by comparison of permeate compositions divided by feed compositions of water over biodiesel-methanol mixture as follows: 


$$
\alpha=\frac{\left(W_{p} / M_{p}\right)}{\left(W_{f} / M_{f}\right)}
$$

where $W_{p}$ and $M_{p}$ are the concentrations (\%,w/w) of water and biodiesel-methanol mixtures in permeate, and $W_{f}$ and $M_{f}$ are the concentrations of water and biodiesel-methanol mixtures in the feed, respectively.

\section{Results and Discussion}

\subsection{Characterization}

The modification of $\mathrm{BC}$ by filing the pores of $\mathrm{BC}$ membrane with alginate and cross linking with $\mathrm{CaCl}_{2}$ significantly changed physico-chemical properties of the membrane. The thickness of the BCA was increased to $332 \mu \mathrm{m}$ (or about 6 folds of that of the unmodified BC membrane) [20]. The comparison of surface and cross-sectional views between the $\mathrm{BC}$ and the $\mathrm{BCA}$ membranes are shown in Fig. 2. The BCA membrane was thicker and had a more compact layer structure after the modification with alginate. The average pore size was reduced to about $3 \mathrm{~nm}$ (or approximately $1 / 10$ of that of the unmodified $\mathrm{BC}$ membrane) [20].
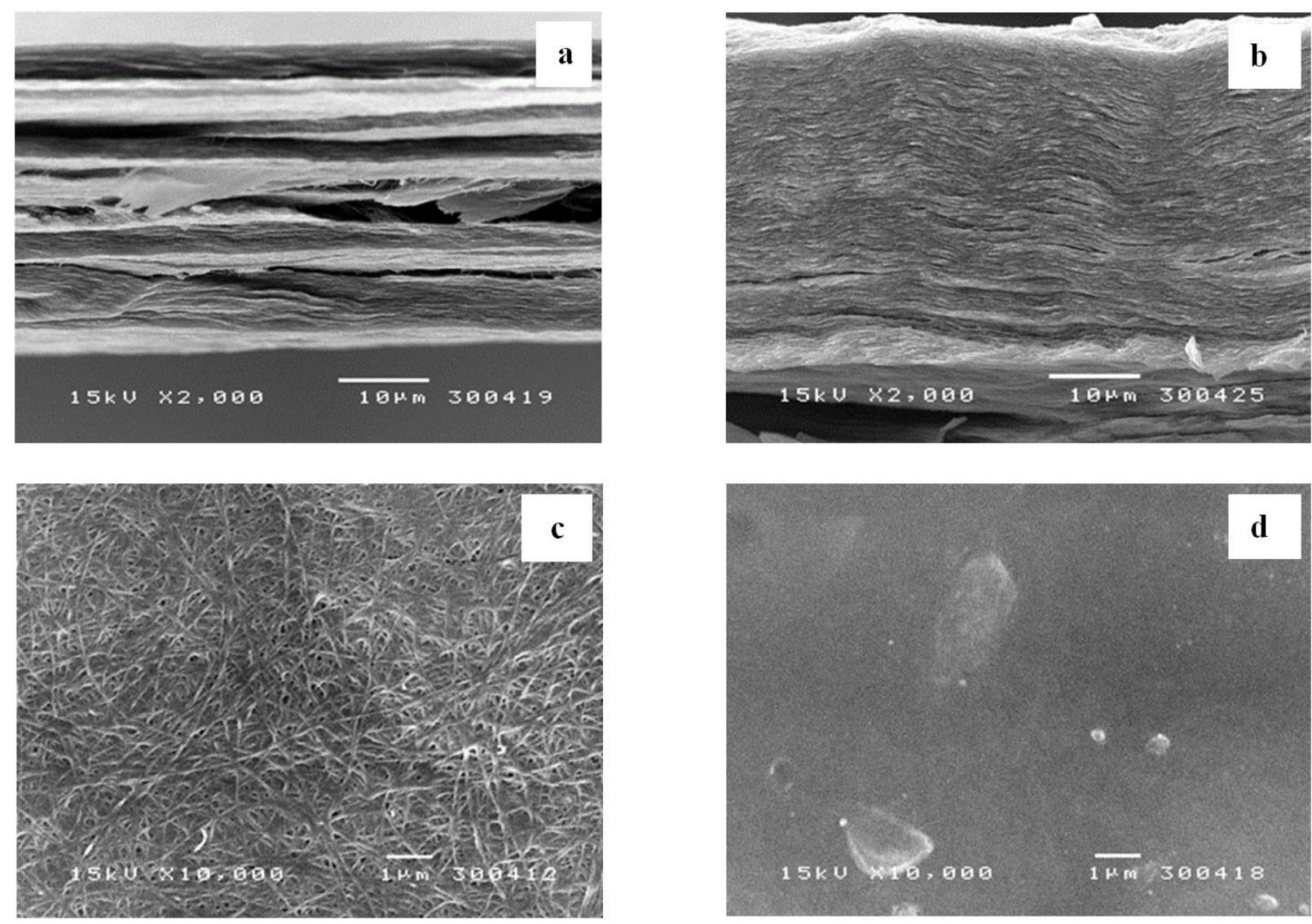

Fig. 2. SEM images of cross-sectional morphology of BC (a) and BCA (b) at the magnification of 2,000 $\times$ and surface morphology of BC (c) and BCA (d) at the magnification of 10,000 $\times$.

The comparison of the contact angles of water on the BC and BCA membranes are shown in Fig. 3 . The higher the surface wettability of the membrane, the smaller the water contact angle against the material surface. The average values of water contact angles of BC and BCA membranes were $\sim 68^{\circ}$ and $\sim 56^{\circ}$, which indicated that the BCA membranes were more hydrophilic than the $\mathrm{BC}$ membrane [20]. 

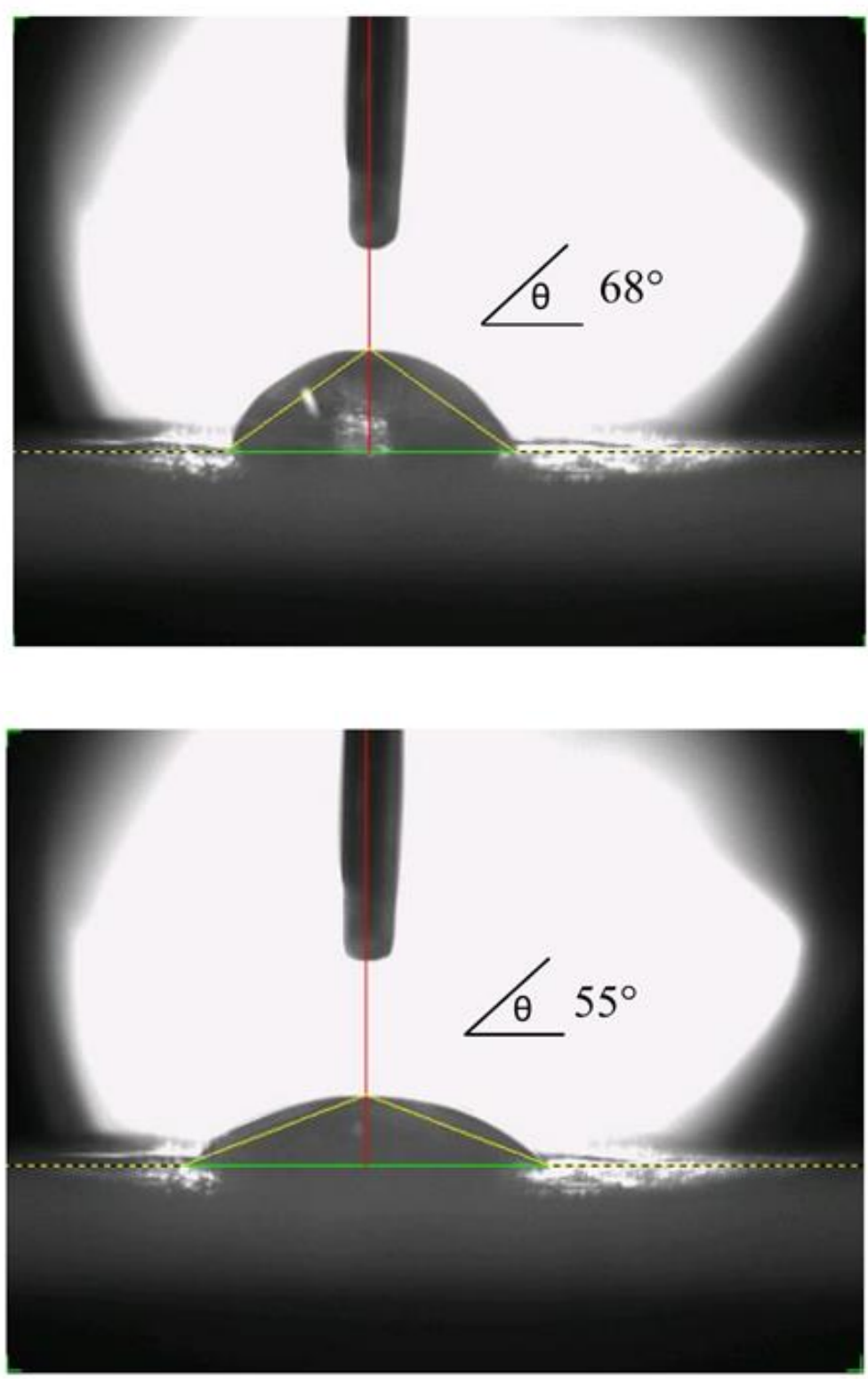

Fig. 3. The contact angle between water and the surface of $\mathrm{BC}$ membrane (top) and $\mathrm{BCA}$ membrane (bottom).

\subsection{Dehydration of Biodiesel-Methanol Mixtures}

\subsubsection{Comparison between BCA and $\mathrm{BC}$ membranes}

The pervaporation performances for dehydration of biodiesel-methanol mixtures by using the BCA and BC membranes under the operating conditions: $5 \%$ and $10 \% \mathrm{w} / \mathrm{w}$ water in the initial feed, $30{ }^{\circ} \mathrm{C}$ and at the permeate pressure of $10 \mathrm{mmHg}$ are shown in Table 1 . Biodiesel is a relatively large molecule compared to methanol and water. It was found that the biodiesel $(98.92 \%(\mathrm{w} / \mathrm{w})$ methyl ester (C10:0)) could not pass through $\mathrm{BC}$ and $\mathrm{BCA}$ membranes into the permeate (100\% rejection of biodiesel by the membranes), whereas methanol and water could diffuse through the membranes and pass into the permeate with a difference in content (Fig. 4). Due to the denser structure, the total permeate fluxes of the BCA membrane were considerably lower than those of the $\mathrm{BC}$ membrane. The total permeate flux of the BCA membrane was about $148.2 \mathrm{~g} /\left(\mathrm{m}^{2} \mathrm{~h}\right)$ or approximately $1 / 88$ of that of the unmodified BC membrane. However, the significant improved separation performance was achieved by using the BCA membrane. The considerable increase in water content in the permeate when using the BCA membrane is shown in Fig. 4, in which the 
concentration of water in the permeate was significantly enhanced to about $95 \%(\mathrm{w} / \mathrm{w})$, whereas that of the BC membrane was only 6-11\% (w/w) (Table 1). The water selectivity of the BCA membranes was 180.54332.05, which was considerable much higher than that of the unmodified $\mathrm{BC}$ membrane. According to the modification, alginate gel filled in the BC fibril network and physical intermolecular interactions might be formed between the hydroxyl groups of BC fibers and carboxyl groups of alginate [20, 21], resulting in a strong and dense network structure with greater hydrophilicity. As a result, the BCA membrane showed superior higher affinities for water and could effectively separate water from methanol and biodiesel.

\subsubsection{Effect of water content in feed}

The effects of water content in feed on the membrane separation performances for biodiesel-methanol mixtures were determined. The data are presented as the mean value \pm standard deviation of five samples (Table 1). The initial water contents in the feeds were 5 and $10 \%(\mathrm{w} / \mathrm{w})$. The experiments were conducted at $30{ }^{\circ} \mathrm{C}$ and $10 \mathrm{mmHg}$. The total flux and water flux increased with the increase of water in the feed from 5 to $10 \%(\mathrm{w} / \mathrm{w})$. The water permeate flux of the BCA membrane relatively increased from 139.8 to 149.6 $\mathrm{g} /\left(\mathrm{m}^{2} \mathrm{~h}\right)$, whereas the water permeate flux of the BC membrane considerably increased from 811.6 to $1586.4 \mathrm{~g} /\left(\mathrm{m}^{2} \mathrm{~h}\right)$. From the results, the total flux, the water flux and water content increased with increasing water content in the feed solution; however, a relatively drop in the water selectivity was observed. It was suggested that water in feed could make hydrophilic membrane in a swollen state, which cause an increase in permeate rate and a lower selectivity [20]. Since the BCA membrane has a strong and denser network structure than the $\mathrm{BC}$ membrane, the effects of membrane swelling was less. It is demonstrated that the water content in feed solution could be a dominant factor in the pervaporation performance of the hydrophilic membranes, leading to a decline in selectivity.

Table 1. Summary of pervaporation performance of $\mathrm{BC}$ membrane and $\mathrm{BCA}$ membranes under operating conditions at $30{ }^{\circ} \mathrm{C}, 5$ and $10 \%(\mathrm{w} / \mathrm{w})$ water in feed and permeate pressure of $10 \mathrm{mmHg}$.

\begin{tabular}{|c|c|c|c|c|c|}
\hline Membrane & $\begin{array}{c}\text { Water content } \\
\text { in feed } \\
(\% \mathrm{w} / \mathrm{w})\end{array}$ & $\begin{array}{l}\text { Total flux } \\
{\left[\mathrm{g} /\left(\mathrm{m}^{2} \mathrm{~h}\right)\right]}\end{array}$ & Water flux $\left[g /\left(m^{2} h\right]\right.$ & $\begin{array}{l}\text { Water in permeate } \\
(\% \mathrm{w} / \mathrm{w})\end{array}$ & Selectivity \\
\hline \multirow[t]{2}{*}{$\mathrm{BC}$} & 5 & $13102.3 \pm 45.7$ & $811.6 \pm 9.7$ & $6.19 \pm 0.08$ & $1.24 \pm 0.02$ \\
\hline & 10 & $14243 \pm 25.9$ & $1586.4 \pm 5.9$ & $11.13 \pm 0.05$ & $1.13 \pm 0.01$ \\
\hline \multirow[t]{2}{*}{$\mathrm{BCA}$} & 5 & $148.2 \pm 2.8$ & $139.8 \pm 2.2$ & $94.46 \pm 0.39$ & $332.05 \pm 31.23$ \\
\hline & 10 & $157.1 \pm 1.4$ & $149.6 \pm 1.4$ & $95.25 \pm 0.29$ & $180.54 \pm 12.48$ \\
\hline
\end{tabular}

\subsubsection{Effect of temperature}

The effects of the operating temperatures on the membrane separation performances for biodieselmethanol mixtures were evaluated. The data are presented as the mean value \pm standard deviation of five samples. Figure 5 shows the effect of temperature varied from 30 to $60{ }^{\circ} \mathrm{C}$ on the separation performance of BCA membrane. The flux increased with increasing temperature for two feed concentrations (Fig. 5(a)). From the results, the maximum flux $\left(251 \mathrm{~g} /\left(\mathrm{m}^{2} \mathrm{~h}\right)\right)$, was achieved with a feed containing $10 \%(\mathrm{w} / \mathrm{w})$ water at $60^{\circ} \mathrm{C}$. The increase in pervaporation flux with increasing operating temperatures could be explained by the enhanced average kinetic energy of the molecules and faster molecular motion at higher temperatures, as described by the Arrhenius relationship [22]. Mass transfer coefficient of components in the liquid and sorption of components into the membrane could also increase with increasing feed temperature. In addition, increasing the operating temperature makes polymer chains more flexible, allowing more free space between the polymers, resulting in higher diffusivity [23]. The increase in temperature also caused the decrease in selectivity as shown in Fig. 5(b). The similar results were previously reported in pervaporation studies of BC and BC composite membranes [20, 24, 25]. 

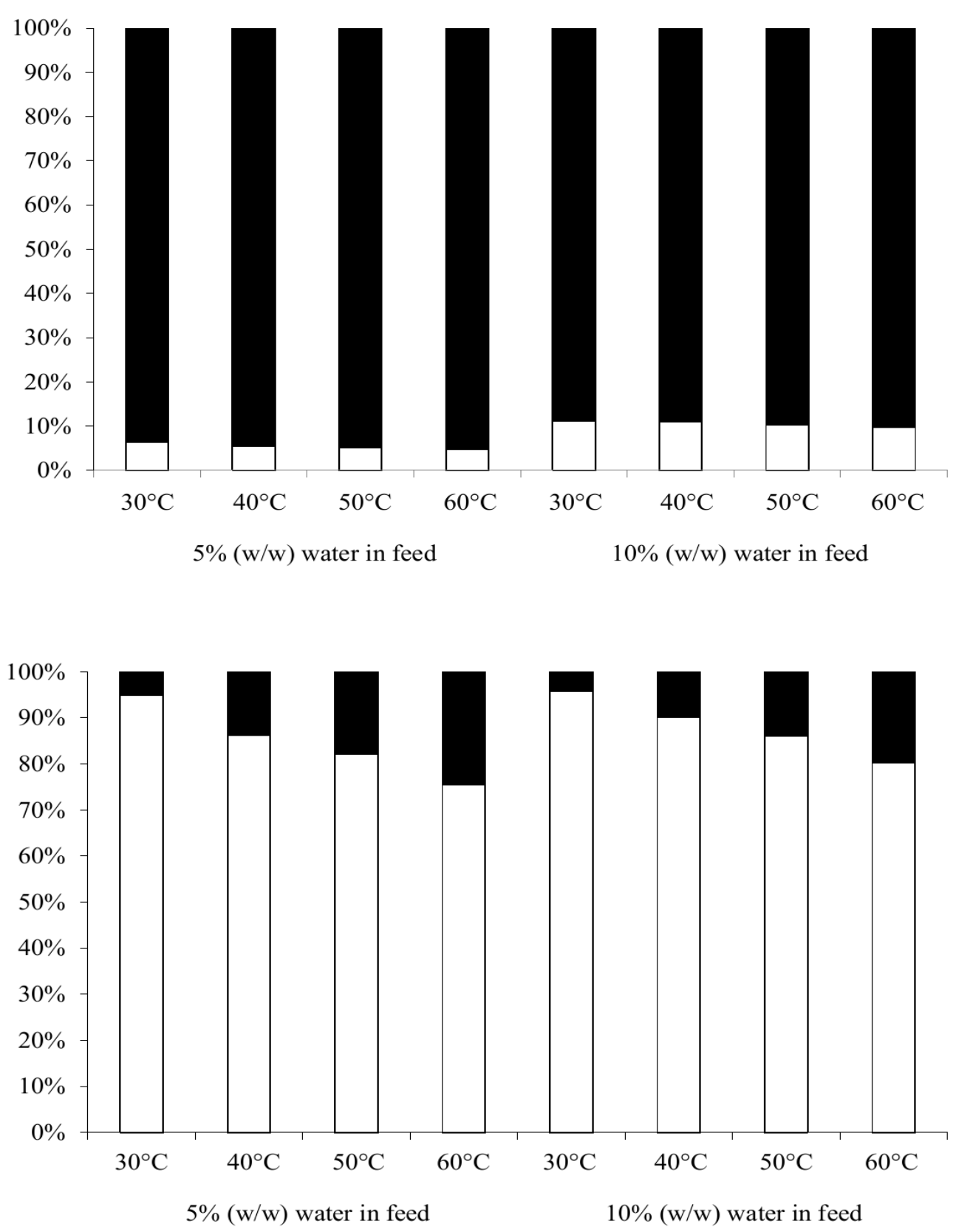

Fig. 4. Permeate composition of BC membrane (top) and BCA membrane (bottom): water ( $\square$ ) and methanol ( ). Pervaporation was performed at $5 \%$ and $10 \%$ water concentration $(\mathrm{w} / \mathrm{w})$ in the feed, $30{ }^{\circ} \mathrm{C}$ and $10 \mathrm{mmHg}$ permeate pressure. 

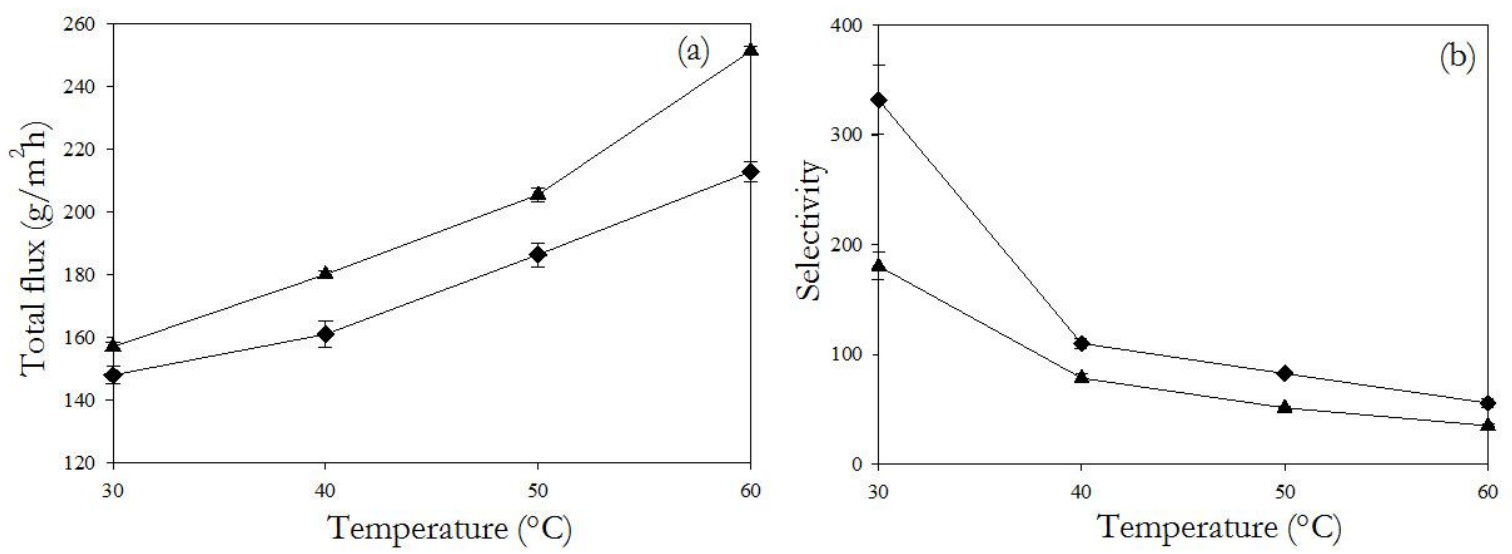

Fig.5. Effect of temperature on pervaporation performance of BCA membrane. The pervaporation performance was examined in terms of total permeate flux (a) and selectivity (b). Pervaporation was performed at $5 \%(\boldsymbol{\nabla})$ and $10 \%(\boldsymbol{\Delta})$ water concentration $(\mathrm{w} / \mathrm{w})$ in the feed and $10 \mathrm{mmHg}$ permeate pressure.

\section{Conclusion}

Bacterial cellulose-alginate (BCA) nanocomposite film was applied as a selective membrane in order to separate water from biodiesel-methanol mixtures using pervaporation. According to the modification, alginate gel filled in the $\mathrm{BC}$ fibril network and intermolecular interactions was formed between the hydroxyl groups of $\mathrm{BC}$ fibers and carboxyl groups of alginate, resulting in a strong and dense network structure with greater hydrophilicity. As a result, the BCA membrane showed superior higher affinities for water and could effectively separate water from methanol and biodiesel. Although the permeate flux was relatively lower, a considerable increase in water separation from biodiesel and methanol was achieved in the BCA membrane system as compared to those of the $\mathrm{BC}$ membrane. An increase in the temperature or amount of water in the feed solution resulted in a higher permeate flux but a lower selectivity. The BCA membrane could be successfully used to separate water from a biodiesel-methanol mixtures of methyl ester (C10:0) and methanol containing $5 \%(\mathrm{w} / \mathrm{w})$ water under the operating condition at a permeate pressure of 10 $\mathrm{mmHg}$ and $30^{\circ} \mathrm{C}$ with a water selectivity of 332 and total permeate flux of $148 \mathrm{~g} /\left(\mathrm{m}^{2} \mathrm{~h}\right)$.

\section{Acknowledgements}

The authors are grateful for the financial support from the Royal Golden Jubilee Ph.D. program from the Thailand Research Fund and the National Research Council of Thailand (NRCT).

\section{References}

[1] J. Marchetti, V. Miguel, and A. Errazu, "Possible methods for biodiesel production," Renew. Sust. Energ. Rev., vol. 11, no. 6, pp. 1300-1311, 2007.

[2] S. Chongkhong, C. Tongurai, and P. Chetpattananondh, "Continuous esterification for biodiesel production from palm fatty acid distillate using economical process," Renewable Energy, vol. 34, no. 4, pp. 1059-1063, 2009.

[3] P. Jasen and J. M. Marchetti, "Kinetic study of the esterification of free fatty acid and ethanol in the presence of triglycerides using solid resins as catalyst," International Journal of Low-Carbon Technologies, vol. 7, no. 4, pp. 325-330, 2012.

[4] M. W. Mumtaz, A. Adnan, Z. Mahmood, H. Mukhtar, M. F. Malik, F. A. Qureshi, and A. Raza, "Biodiesel from waste cooking oil: Optimization of production and monitoring of exhaust emission levels from its combustion in a diesel engine," Int. J. Green Energy, vol. 9, no. 7, pp. 685-701, 2012.

[5] Y. Liu, H. Wu, Y. Yan, L. Dong, M. Zhu, and P. Liang, "Lipase-catalyzed transesterification for biodiesel production in ionic liquid [Emim]Tfo," Int. J. Green Energy, vol. 10, no. 1, pp. 63-71, 2013.

[6] J. M. Marchetti and A. F. Errazu, "Comparison of different heterogeneous catalysts and different alcohols for the esterification reaction of oleic acid," Fuel, vol. 87, no. 15-16, pp. 3477-3480, 2008. 
[7] S. J. Kwon, K. M. Song, W. H. Hong, and J. S. Rhee, "Removal of water produced from lipasecatalyzed esterification in organic solvent by pervaporation," Biotechnol. Bioeng., vol. 46, no. 4, pp. 393 395, 1995.

[8] B. Sarkar, S. Sridhar, K. Saravanan, and V. Kale, "Preparation of fatty acid methyl ester through temperature gradient driven pervaporation process," Chem. Eng. J., vol. 162, no. 2, pp. 609-615, 2010.

[9] B. Van der Bruggen and P. Luis, "Chapter Four-Pervaporation," in Progress in Filtration and Separation, S. Tarleton, Ed. Oxford: Academic Press, 2015, pp. 101-154.

[10] L. M. Vane, "Separation technologies for the recovery and dehydration of alcohols from fermentation broths," Biofuel. Bioprod. Bior., vol. 2, no. 6, pp. 553-588, 2008.

[11] P. Das and S. K. Ray, "Synthesis and characterization of biopolymer based mixed matrix membranes for pervaporative dehydration," Carbobydr. Polym., vol. 103, pp. 274-284, 2014.

[12] K. F. Yee, Y. T. Ong, A. R. Mohamed, and S. H. Tan, "Novel MWCNT-buckypaper/polyvinyl alcohol asymmetric membrane for dehydration of etherification reaction mixture: Fabrication, characterisation and application," J. Membr. Sci., vol. 453, pp. 546-555, 2014.

[13] S.-H. Huang, Y.-Y. Liu, Y.-H. Huang, K.-S. Liao, C.-C. Hu, K.-R. Lee, and J.-Y. Lai, "Study on characterization and pervaporation performance of interfacially polymerized polyamide thin-film composite membranes for dehydrating tetrahydrofuran," J. Membr. Sci., vol. 470, pp. 411-420, 2014.

[14] J. Albo, J. Wang, and T. Tsuru, "Application of interfacially polymerized polyamide composite membranes to isopropanol dehydration: Effect of membrane pre-treatment and temperature," $J$. Membr. Sci., vol. 453, pp. 384-393, 2014.

[15] P. Kanti, K. Srigowri, J. Madhuri, B. Smitha, and S. Sridhar, "Dehydration of ethanol through blend membranes of chitosan and sodium alginate by pervaporation," Sep. Purif. Technol., vol. 40, no. 3, pp. 259-266, 2004.

[16] V. T. Magalad, G. S. Gokavi, C. Ranganathaiah, M. H. Burshe, C. Han, D. D. Dionysiou, M. N. Nadagouda, and T. M. Aminabhavi, "Polymeric blend nanocomposite membranes for ethanol dehydration-Effect of morphology and membrane-solvent interactions," J. Membr. Sci., vol. 430, pp. 321-329, 2013.

[17] T. Uragami, T. Saito, and T. Miyata, "Pervaporative dehydration characteristics of an ethanol/water azeotrope through various chitosan membranes," Carbohydr. Polym., vol. 120, pp. 1-6, 2015.

[18] A. M. Sajjan, H. Premakshi, and M. Y. Kariduraganavar, "Synthesis and characterization of GTMAC grafted chitosan membranes for the dehydration of low water content isopropanol by pervaporation," J. Ind. Eng. Chem., vol. 25, pp. 151-161, 2014.

[19] W. Lin, Q. Li, and T. Zhu, "New chitosan/Konjac glucomannan blending membrane for application in pervaporation dehydration of caprolactam solution," J. Ind. Eng. Chem., vol. 18, no. 3, pp. 934-940, 2012.

[20] T. Suratago, S. Taokaew, N. Kanjanamosit, K. Kanjanaprapakul, V. Burapatana, and M. Phisalaphong, "Development of bacterial cellulose/alginate nanocomposite membrane for separation of ethanolwater mixtures," J. Ind. Eng. Chem., vol. 32, pp. 305-312. 2015.

[21] L. Zhou, D. Sun, L. Hu, Y. Li, and J. Yang, "Effect of addition of sodium alginate on bacterial cellulose production by Acetobacter xylinum," J. Ind. Microbiol. Biotechnol., vol. 34, no. 7, pp. 483-489, 2007.

[22] Z. Huang, H.-m. Guan, W. lee Tan, X.-Y. Qiao, S. Kulprathipanja, "Pervaporation study of aqueous ethanol solution through zeolite-incorporated multilayer poly (vinyl alcohol) membranes: effect of zeolites," J. Membr. Sci., vol. 276, no. 1, pp. 260-271, 2006.

[23] C.-L. Lai, R.-M. Liou, S.-H. Chen, C.-Y. Shih, J. Chang, C.-H. Huang, M.-Y. Hung, and K.-R. Lee, "Dehydration of ethanol/water mixture by asymmetric ion-exchange membranes," Desalination, vol. 266, no. 1, pp. 17-24, 2011.

[24] V. Dubey, L. K. Pandey, and C. Saxena, "Pervaporative separation of ethanol/water azeotrope using a novel chitosan-impregnated bacterial cellulose membrane and chitosan-poly (vinyl alcohol) blends," $J$. Membr. Sci., vol. 251, no. 1, pp. 131-136, 2005.

[25] L. K. Pandey, C. Saxena, and V. Dubey, "Studies on pervaporative characteristics of bacterial cellulose membrane," Sep. Purif. Technol., vol. 42, no. 3, pp. 213-218, 2005. 